УДК 364.4-054.57(571.53)

О. Г. Седых

Байкальский государственный университет, г. Иркутск, Российская Федерация

К. Д. Ильина

Байкальский государственный университет,

г. Иркутск, Российская Федерация

\title{
СОЦИАЛЬНАЯ ПОДДЕРЖКА ПРЕДСТАВИТЕЛЕЙ КОРЕННЫХ МАЛОЧИСЛЕННЫХ НАРОДОВ В ИРКУТСКОЙ ОБЛАСТИ
}

\begin{abstract}
АНнОТАЦИЯ. В статье рассматриваются коренные малочисленные народы как одна из самых незащищенных групп населения в Иркутской области. Показаны специфические особенности исследуемой категории населения: проживание на определенной географической территории; сохранение традиционного образа жизни, хозяйствования и промыслов; осознание себя самостоятельной этнической общностью; наличие определенных природных ресурсов. Представлены основные социально-экономические проблемы исследуемой категории населения. Сложности в социально-экономическом развитии коренных малочисленных народов существенны и в первую очередь связаны с ограничением транспортной доступности и низкой инфраструктурной обустроенностью, невысоким уровнем доходов и высоким уровнем заболеваемости. Проанализировано проведенное авторами социологическое исследование. Полученные результаты исследования обозначили проблемы оказания социальной помощи коренным малочисленным народам и позволили оценить нынешнее положение коренных малочисленных народов в Иркутской области. Оказываемые меры социальной поддержки исследуемой категории населения являются недостаточными для полноценного развития и сохранения традиционной культуры.
\end{abstract}

КЛЮЧЕВЫЕ СЛОВА. Коренные малочисленные народы; Иркутская область; меры социальной поддержки; образование; здравоохранение; социологическое исследование; слабозащищенные группы населения; неблагоприятные условия; социально-экономические проблемы; уровень жизни населения.

ФИНАНСИРОВАНИЕ. Работа выполнена при финансовой поддержке Федерального государственного бюджетного учреждения «Российский фонд фундаментальных исследований” на реализацию в 2017 г. научного проекта № 17-03-00477/17 «Влияние идей патернализма на поведенческие стратегии: исследование практик социального иждивенчества и социального паразитизма отдельных категорий населения" (протокол № 4 (186) от 15 марта 2017 г.).

ИНФОРМАЦИЯ О СТАТЬЕ. Дата поступления 25 апреля 2017 г.; дата принятия к печати 19 мая 2017 г.; дата онлайн-размещения 23 июня 2017 г.

O. G. Sedykh

Baikal State University, Irkutsk, Russian Federation

K. D. Ilyina

Baikal State University,

Irkutsk, Russian Federation

\section{SOCIAL SUPPORT OF REPRESENTATIVES OF INDIGENOUS LOW-NUMBERED ETHNIC PEOPLES IN IRKUTSK OBLAST}

ABSTRACT. The paper considers indigenous low-numbered small peoples as one of the most vulnerable population groups in Irkutsk Oblast. It show the specific features of the population category under study: living in a specific geographical area; preservation of the traditional way of life, economic management and crafts; self-perception

(C) О. Г. Седых, К. Д. Ильина, 2017

\section{Baikal Research Journal}


as a an independent ethnic community; availability of certain natural resources. It presents the main socio-economic problems of the population category under study. Difficulties in the socio-economic development of indigenous low-numbered small peoples are significant and primarily related to restriction of transport accessibility and low infrastructure, low incomes and high incidence of disease. The article analyses the sociological investigation carried out by the authors. The investigation results obtained specify the problems of rendering social assistance to the indigenous low-numbered small peoples and allow to evaluate the current situation of the indigenous low-numbered small peoples in Irkutsk Oblast. The measures rendered in terms of social support of the population category under study are insufficient for full-scale development and preservation of the traditional culture.

KEYWORDS. Indigenous low-numbered peoples; Irkutsk Oblast; measures of social support; education; health care; sociological investigation; vulnerable groups of population; unfavorable conditions; socio-economic problems; social standard of living. ARTICLE INFO. Received April 25, 2017; accepted May 19, 2017; available online June 23, 2017.

Российская Федерация - многонациональное государство, в котором проживает более 170 народов. Из числа этих народов законодательство Российской Федерации выделяет коренные малочисленные народы в отдельную социальную группу населения, нуждающуюся в особой государственной защите и государственной поддержке.

Термин «Коренные народы Севера, Сибири и Дальнего Востока Российской Федерации" включает несколько аспектов: этнический, географический, демографический, культурный и социальный. Это самая короткая формулировка данного понятия, которая встречается чаще всего в научно-популярной литературе $[1$, c. $243 ; 2$, с. 31$]$.

Под коренными малочисленными народами (КMH) РФ признаются народы, проживающие на территориях традиционного расселения своих предков, сохраняющие традиционные образ жизни, хозяйствование и промыслы, насчитывающие в РФ менее 50 тыс. человек и осознающие себя самостоятельными этническими общностями ${ }^{1}$. Данные социальные группы обладают специфическими особенностями, определяющимися не только отношением к тому или иному этносу, но и проживанием на определенной географической территории, обладающей индивидуальными (исключительными) признаками (наличием определенных природных ресурсов, объектов животного мира, памятников природы и пр.). В большинстве случаев природное богатство этих территорий связано с труднодоступностью, сложными климатическими условиями и, что самое главное, хрупкостью существующего экобаланса, его крайней незащищенностью перед угрозой промышленных разработок природных богатств ${ }^{2}$.

На территории Иркутской области в 8 муниципальных районах проживает около 2 тыс. представителей КМН: Катангский (эвенки, 472 чел.), Нижнеудинский (тофы, 655 чел.). Качугском (245 чел.), Казачинско-Ленском (50 чел.), г. Бодайбо и район (79 чел.), Мамско-Чуйском (37 чел.) и Усть-Кутском (45 чел.).

Представители коренных народов проживают в удаленных и труднодоступных местностях, например:

${ }^{1} \mathrm{O}$ территориях традиционного природопользования коренных малочисленных народов Севера, Сибири и Дальнего Востока Российской Федерации [Электронный ресурс] : федер. закон от 7 мая 2001 г. № 49-Ф3 // СПС «КонсультантПлюс» .

2 Доклад на заседание фракции «Единая Россия» в Законодательном Собрании Иркутской области по вопросу «Коренные малочисленные народы Иркутской области: социально-экономическая политика для сохранения и развития территорий» [Электронный pecypc]. URL: http://irkobl.ru/sites/ economy/prostranstvennoe-razvitie/narod_Sibiri/doklad_o_KMNS.docx.

\section{Baikal Research Journal}

электронный научный журнал Байкальского государственного университета 
- в Нижнеудинском районе (от райцентра до населенных пунктов Алыгджер, Верхняя Гутара и Нерха 300 км, связь автозимником и вертолетом);

- в Катанском районе до населенных пунктов КМН до 500 км. Связь с самим районом круглогодично осуществляется воздушным транспортом. При этом, требуется реконструкция аэропорта Ербогачен из-за ненадлежащего состояния взлетно-посадочной полосы и аэропортового комплекса (объем инвестиций 1,3 млрд р.).

В большинстве своем коренные народы занимаются традиционными видами деятельности: оленеводство, охотничьим промыслом, выловом рыбы, сбором дикоросов.

В местах проживания КМН среднедушевые денежные доходы у представителей данной категории населения почти в два раза ниже соответствующих среднеобластных показателей. Например, номинальные среднедушевые доходы КМH в Катангском районе оцениваются около 10,5 тыс. р., Нижнеудинском около 16 тыс. р., в среднем по области этот показатель составляет 22 тыс. р.

Проблемы в социально-экономическом развитии КМНС существенны и в первую очередь связаны с:

- ограничением транспортной доступности и низкой инфраструктурной обустроенностью;

- невысоким уровнем доходов;

- высоким уровнем заболеваемости.

Ведущую роль в обеспечении материальными благами у северных народов играет иждивенчество, личное подсобное хозяйство (особенно высока его роль у тофаларов) и пособия. Доход от трудовой деятельности имеют меньше четверти тофаларов и треть эвенков. Это связано с низкой занятостью населения. Единственным источником денежных поступлений во многих семьях является выплата детских пособий. Разница в доходах между тофаларами и остальным населением буквально кричащая [3, с. $113 ; 4$, с $134 ; 5$, с. 141].

Образовательный уровень представителей КМН области невысок - в 3-3,5 раза ниже средне областного. В Тофаларии за последние 10 лет высшее и среднее специальное образование получили 15 человек, однако среди них нет ни одного юриста или экономиста, столь необходимых в период современного возрождения местного национального самоуправления.

В настоящее время наблюдается снижение уровня общего и профессионально технического образования коренных малочисленных народов. Почти 48 \% представителей имеют только начальное и неполное среднее образование, $17 \%$ не имеют даже начального образования.

Существующая сеть общеобразовательных учреждений не обеспечивает потребности коренных малочисленных народов в образовании. Практически во всех районах проживания этих народов сокращается количество дневных общеобразовательных школ. Школы испытывают недостаток педагогических кадров, слабо оснащены современными техническими средствами обучения. Особой проблемой является обучение родному языку, который в школах изучают (в целом по регионам Севера) не более 50 \% учащихся. Увеличилось количество школ, находящихся в аварийном состоянии и требующих капитального ремонта. В ряде районов проживания коренных малочисленных народов отсутствуют средние специальные учебные заведения с ориентацией на подготовку специалистов для традиционных отраслей хозяйствования и промыслов, также отсутствуют национальные кадры в местах компактного проживания коренных малочисленных народов Иркутской области [6, с. 42]. Требуется повышение уровня подготовки кадров из лиц коренных малочисленных народов Иркутской области, имеющих высшее и среднее

\section{Baikal Research Journal}


профессиональное образование, а также повышение уровня квалификации педагогического персонала в знании эвенкийского и тофаларского языков.

Меры по развитию системы охраны здоровья, включая профилактику заболеваний среди малочисленных народов, проводятся в недостаточном объеме из-за нехватки финансовых средств на выезды медицинских бригад и приобретение медикаментов [7, с. 94; 8, с. 62]. Высокие тарифы на авиационные перевозки и ограниченность времени использования зимних дорог не позволяют вести регулярные медосмотры и профилактические мероприятия, что способствует распространению и таких заболеваний, как чесотка, гепатит, туберкулез и другие.

Для детей из числа коренных малочисленных народов, проживающих в условиях экстремально дискомфортного климата Севера, ограниченной транспортной доступности, характерен очень высокий уровень заболеваемости - в 2,0-2,5 раза выше, чем в среднем по Иркутской области (заболевания органов дыхания, сердечно-сосудистой системы, социально-значимые заболевания, стоматологические заболевания).

Из-за недостатка врачей узких специальностей осмотры и лечение детей в периферийных населенных пунктах проводят педиатры или медицинские сестры. До $12 \%$ детей и подростков находится на диспансерном учете. На их обследование и лечение в районных и областных больницах у подавляющего большинства семей, имеющих среднедушевой доход менее 1 тыс. р. в месяц, нет средств [9, с. 45].

Кроме того, под влиянием неблагоприятных условий Севера у многих детей происходит отставание возрастного развития иммунной системы, а значительная часть территорий, особенно лесоболотных ландшафтов равнин, является очагами природных инфекций. Все это требует постоянного контроля за санитарно-эпидемиологическими условиями проживания и существенных дополнительных мер по профилактике заболеваний и оздоровлению населения из числа малочисленных народов.

Процессы ассимиляции коренных малочисленных народов Иркутской области с другими народами негативно сказались не только на языковой ситуации, но и способствовали утрате многих элементов их национальной культуры. Эвенки и тофалары теряют свой язык, свою традиционную культуру [10, с. 62]. Для решения проблемы были созданы центры, основными целями и задачами которых являются изучение, сохранение, развитие и популяризация самобытной национальной культуры коренных малочисленных народов.

Ж Кллиный фонд большинства сел в традиционных местах проживания ветхий и, как правило, довоенной постройки. Состояние жилищного фонда, недостаточные темпы его ремонта и строительства нового жилья в местах традиционного проживания не позволяют прогнозировать существенное улучшение жизни коренных малочисленных народов. При низком среднедушевом доходе многие из семей, особенно многодетные, остро нуждаются в улучшении жилищных условий. Люди живут в ветхих довоенной постройки домах. ЖКилая площадь в расчете на одного человека составляет не более $6 \mathrm{~m}^{2}$.

В Тофаларии практически отсутствуют дороги (90\% территории - среднегорные таежные ландшафты, остальная часть - горная тундра), в связи с чем основная связь осуществляется посредством малой авиации, так как места традиционной хозяйственной деятельности (охотничье-промысловые базы, заготовительные участки) находятся на значительном удалении от мест традиционного проживания коренных малочисленных народов (80-150 км).

В Катангской районе протяженность между поселками и местами традиционной хозяйственной деятельности (стойбища, охотничье-промысловые базы) составляет от 100 до 200 км.

\section{Baikal Research Journal}

электронный научный журнал Байкальского государственного университета 
Решение проблем социального развития коренных малочисленных народов в условиях рыночных отношений, повышения уровня их жизни может быть обеспечено только при целенаправленной государственной политике с участием различных органов государственной власти и органов местного самоуправления, межотраслевой координации их действий, а в целом путем реализации программно-целевого подхода к решению проблем $[11$, с. $245 ; 12$, с. 73$]$.

Оценивая и анализируя современную ситуацию проблем коренных малочисленных народов Иркутской области и оказываемых мер социальной помощи со стороны государства, мы решили проанализировать удовлетворенность социальной поддержкой коренными малочисленными народами в Иркутской области, поэтому в марте 2017 г. было проведено исследование.

Цель социологического исследования - изучить степень удовлетворенности коренных малочисленных народов мерами социальной поддержки со стороны государства. Для того, чтобы достичь желаемого результата в исследовании необходимо было решить такие задачи как: изучить какие меры социальной поддержки оказываются со стороны государства в нашем регионе и определить степень удовлетворенности получателей данных мер. На основании анализа полученных данных мы должны были подтвердить или опровергнуть гипотезу о том, что в нашем регионе недостаточно внимания уделяют решению проблем коренных малочисленных народов. Поскольку мы решили определить степень удовлетворенности мерами социальной поддержки КМН в Иркутской области, то объектом исследования являлись представители коренных малочисленных народов Иркутской области. Так как они проживают в местах отдаленного доступа и связаться с ними крайне сложно, нашу генеральную совокупность составило 11 человек. Генеральная совокупность небольшая, для ее исследования сообразно было использовать сплошное наблюдение (т. е. исследовать все единицы генеральной совокупности).

Так как предметом данного исследования является уровень удовлетворенности формами социальной поддержки коренных малочисленных народов в Иркутской области, то основным источником получения информации выступали коренные малочисленные народы с их мнениями, оценками, взглядами. В данном случае для получения информации субъективного характера наиболее оптимальным и подходящим методом являлся анкетный опрос. Он позволил в короткие сроки и при минимальных затратах исследовать все единицы генеральной совокупности и получить необходимую информацию, подвергнуть ее статистической обработке и последующей интерпретации.

В данном анкетировании приняли участие 11 человек, из них: 2 человека проживают в п. Верхняя Гутара, 1 человек - в п. Нерха и 8 человек - в п. Алыгджер. Возраст респондентов старше 40 лет. Респонденты единогласно решили, что в настоящее время коренным малочисленным народам необходима социальная поддержка со стороны государства и властей.

На вопрос «В какой сфере, по Вашему мнению, лежат основные проблемы коренных малочисленных народов в Иркутской области?» мнения опрошенных разделились следующим образом: большинство предполагают, что в сфере защиты прав и гарантий лежат основные проблемы коренных малочисленных народов, равный показатель отметили жилищную сферу и сферу здравоохранения (рис. 1).

Анализируя полученные результаты можно сделать вывод, что опрошенные относительно недолго пользуются мерами социальной поддержки со стороны государства (от 1 до 3 лет).

Из 11 респондентов 4 человека отметили, что получают компенсацию стоимости проезда к месту прохождения стационарного лечения и обратно, 4 человека отметили, что получают пенсию по старости или социальную пенсию и один чело-

\section{Baikal Research Journal}

электронный научный журнал Байкальского государственного университета 
век отметил, что пользуется перевозкой до охотничьих угодий на вертолете. Анализируя ответы на вопрос о том, на какие цели они расходуют меры социальной помощи: 2 человека отметили, что данную помощь они используют для приобретения сельскохозяйственной техники и снегоходов для общины.

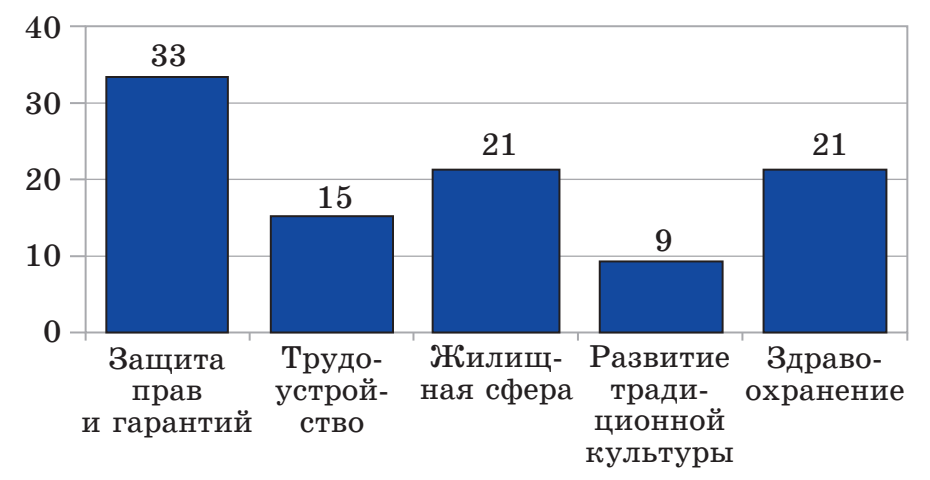

Рис. 1. Распределение ответов на вопрос о проблемных сферах, \%

Изучение мнений о мерах социальной поддержки, в которых нуждаются коренные малочисленные народы, можно сделать вывод, что самой необходимой является помощь в медицинском обследовании и лекарственном обеспечении, приобретении сельскохозяйственной техники и санаторно-курортном лечении.

Далее мы изучили мнения респондентов в чем же состоят трудности для получения социальной помощи от государства и властей Иркутской области. В большинстве случаев трудности возникают в сборе необходимых документов, отдаленностью мест проживания и плохой транспортной доступностью, т. е. у многих просто нет возможности выехать в областной центр.

И в завершении нами был задан вопрос «Какие меры стоит предпринять для повышения эффективности оказания мер социальной помощи коренным малочисленным народам в Иркутской области?». Большинство респондентов (19 \%) отметили, что меры по усовершенствованию законодательства в области социальной помощи коренным малочисленным народам должны быть приняты в первую очередь, так как являются важным фактором развития и сохранения традиций, быта и культуры коренных малочисленных народов. Также главными показателями повышения эффективности мер социальной помощи респонденты отметили улучшение условий жизни, увеличение системы квотирования народных промыслов, усовершенствование проведения медицинского обследования и создание специальных центров для возрождения, развития и сохранения традиционной культуры (рис. 2).

Результаты проведенного социологического исследования позволяют сделать вывод о том, что в Иркутской области коренные малочисленные народы являются одной из самых уязвимых и слабозащищенных групп населения. Большинство из них не пользуются правом на получение различных льгот и выплат в силу незнания законов, своих прав и гарантий, а также неосведомленности и не информированности со стороны администраций районов и власти региона.

В ходе анализа и изучения состояния проблем коренным малочисленных народов можно сделать вывод о том, что самой важной проблемой является медицинское обслуживание и лекарственное обеспечение данных групп населения, а также плохая транспортная доступность, отдаленность мест проживания, недоступность средств связи. Все эти факторы, в свою очередь, приводят к таким проблемам, как неграмотность и необразованность населения, неразвитость социальной инфраструктуры и т. п.

\section{Baikal Research Journal}

электронный научный журнал Байкальского государственного университета 


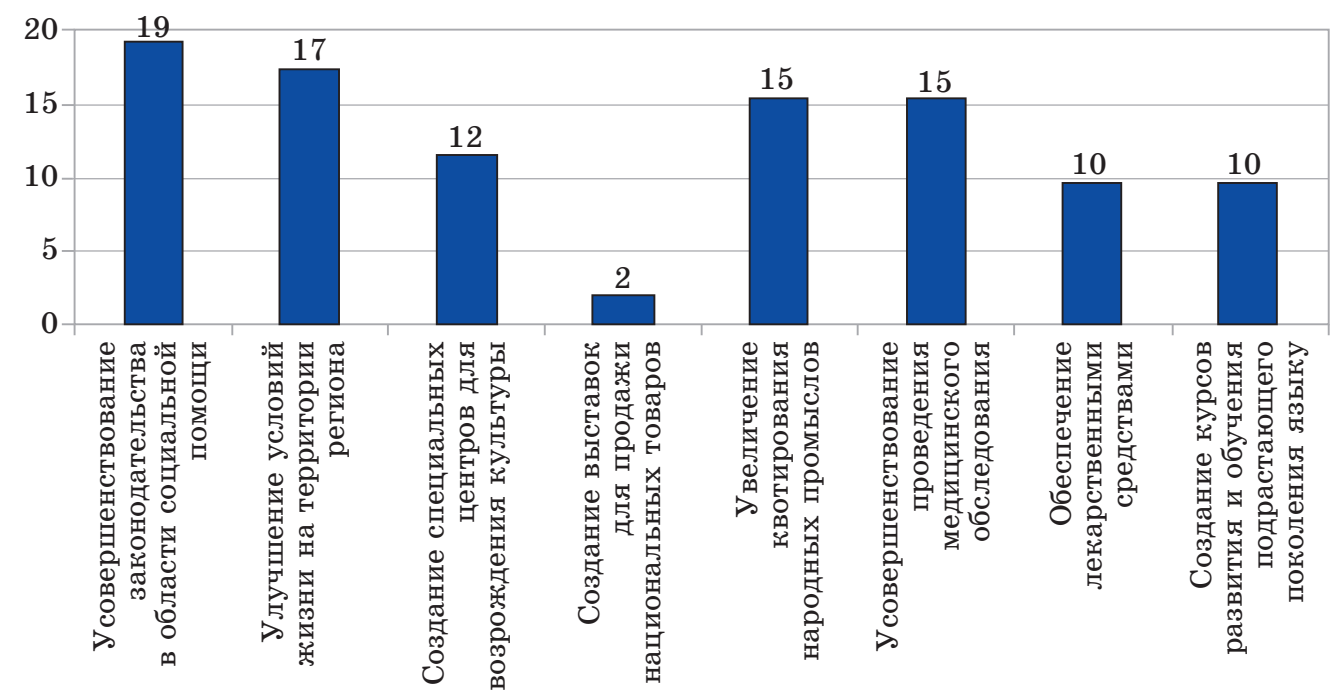

Рис. 2. Распределение ответов на вопрос о принятии необходимых мер для повышения эффективности оказания социальной поддержки коренных малочисленных народов, \%

Оказываемые меры социальной поддержки КМН в Иркутской области являются недостаточными для полноценного развития и сохранения традиционной культуры, недостаточное внимание уделяется решению проблем в области защиты прав и гарантий. По результатам данного исследования можно сделать вывод, что наша гипотеза подтвердилась.

Полученные результаты исследования обозначили проблемы оказания социальной помощи коренным малочисленным народам и позволили оценить нынешнее положение коренных малочисленных народов в Иркутской области.

\section{Список использованной литературы}

1. Сирина А. А. Эвенки и эвены в современном мире: самосознание, природопользование, мировоззрение / А. А. Сирина. - М. : Вост. лит., 2012. - 604 с.

2. Досакаев А. Б. О необходимости законодательного урегулирования определения понятия «коренные малочисленные народы России" / А. Б. Досакаев // Закон и право. 2013. - № 5. - C. 31-33.

3. Галаганов В. П. Организация работы органов социального обеспечения в Российской Федерации : учебник / В. П. Галаганов. - 3-е изд., испр. и доп. - М. : КноРус, 2015. - 152 c.

4. Харючи С. Н. Социальные нормы коренных малочисленных народов Севера России. Обряды, обычаи, ритуалы, традиции, мифы, нормы морали, нормы права : монография / С. Н. Харючи, К. Г. Филант, И. Ю. Антонов. - М. : Юнити-Дана : Закон и право, 2009. -279 c.

5. Снигирева М. А. Программно-целевой метод оказания государственной поддержки коренным малочисленным народам Севера / М. А. Снигирева // Известия Санкт-Петербургского экономического университета. - 2012. - № 6. - С. 141-143.

6. Юдин В. И. Региональный опыт взаимодействия с коренными малочисленными народами Севера / В. И. Юдин // Человеческий капитал. - 2013. - № 8 (56). C. 41-44.

7. Метелева Е. Р. Определение ключевых терминов в социальной сфере / Е. Р. Метелева // Известия Иркутской государственной экономической академии. $-2016 .-$ Т. 26, № 1. - C. 90-98. — DOI: 10.17150/1993-3541.2016.26(1).90-98.

\section{Baikal Research Journal}


8. Зубов Л. А. Медико-социальные проблемы и перспективные направления организации медицинской помощи коренным малочисленным народам труднодоступных территорий Севера / Л. А. Зубов // Экология человека. - 2010. - № 1. - С. 61-64.

9. Модернизация социальной сферы муниципальных образований Сибирского региона как основы повышения качества жизни населения / В. И. Самаруха, А. В. Самаруха, Т. В. Сорокина [и др.]. - Иркутск : Изд-во БГУЭП, 2013. - 270 с.

10. Аверин А. Коренные малочисленные народы Севера, Сибири и Дальнего Востока / А. Аверин // Социальная политика и социальное партнерство. — 2012. - № 8. C. 61-70.

11. Социальное обслуживание населения: ценности, теория, практика : учеб. пособие / под ред. Л. В. Топчего. - М. : Изд-во Рос. гос. соц. ун-та, 2011. — 320 с.

12. Теоретико-методические аспекты исследования качества жизни населения / под ред. Н. М. Токарской, Л. В. Саниной. - Иркутск : Изд-во БГУЭП, 2013. - 180 с.

\section{References}

1. Sirina A. A. Evenki i eveny $v$ sovremennom mire: samosoznanie, prirodopol'zovanie, mirovozzrenie [Evenks and evens in today's context: self-awareness, nature resource management, world outlook]. Moscow, Vostochnaya literature Publ., 2012. 604 p.

2. Dosakayev A. B. On the necessity of legislative regulation of definition of the concept «indigenous low-numbered peoples of Russia». Zakon $i$ pravo = Legislation and Law, 2013, no. 5, pp. 31-33. (In Russian).

3. Galaganov V. P. Organizatsiya raboty organov sotsial'nogo obespecheniya $v$ Rossiiskoi Federatsii [Management of the Social Welfare Institution in the Russian Federation]. $3^{\text {rd }}$ ed. Moscow, KnoRus Publ., 2015. 152 p.

4. Kharyuchi S. N., Filant K. G., Antonov I. Yu. Sotsial'nye normy korennykh malochislennykh narodov Severa Rossii. Obryady, obychai, ritualy, traditsii, mify, normy morali, normy prava [Social norms of indigenous small-numbered peoples of the Russia's North. Rites, habits, rituals, traditions, myths, rules of morality, standards of law]. Moscow, Yuniti-Dana Publ., Zakon i pravo Publ., 2009. 279 p.

5. Snigireva M. A. Program-target method of rendering governmental support to indigenous small-numbered peoples of the North. Izvestiya Sankt-Peterburgskogo ekonomicheskogo universiteta = Bulletin of Saint Petersburg State University of Economics, 2012, no. 6, pp. 141-143. (In Russian).

6. Yudin V. I. Regional experience of cooperation with indigenous small- numbered peoples of the North. Chelovecheskii kapital = Human Capital, 2013, no. 8 (56), pp. 41-44. (In Russian).

7. Meteleva E. R. Determining the key terms of social welfare. Izvestiya Irkutskoi gosudarstvennoi ekonomicheskoi akademii = Bulletin of Irkutsk State Economics Academy, 2016, vol. 26, no. 1, pp. 90-98. DOI: 10.17150/1993-3541.2016.26(1).90-98. (In Russian).

8. Zubov L. A. Medico-social problems and prospective directions of arranging medical aid to indigenous low-numbered peoples in hard-to-reach territories of the North. Ekologiya cheloveka = Human Ecology, 2010, no. 1, pp. 61-64. (In Russian).

9. Samarukha V. I., Samarukha A. V., Sorokina T. V. et al. Modernizatsiya sotsial'noi sfery munitsipal'nykh obrazovanii Sibirskogo regiona kak osnovy povysheniya kachestva zhizni naseleniya [Modernization of the Social Sphere of Municipalities of the Siberian Region as a Basis for Improving Social Standards of Living]. Irkutsk, Baikal State University of Economics and Law Publ., 2013. 270 p.

10. Averin A. Indigenous low-numbered peoples of the North, Siberia and the Far East. Sotsial'naya politika $i$ sotsial'noe partnerstvo = Social Policy and Social Partnership, 2012, no. 8, pp. 61-70. (In Russian).

11. Topchii L. V. (ed.). Sotsial'noe obsluzhivanie naseleniya: tsennosti, teoriya, praktika [Social service: values, theory, practice]. Moscow, Russian State Social University Publ., 2011. 320 p.

12. Tokarskaya N. M., Sanina L. V. (eds). Teoretikometodicheskie aspekty issledovaniya kachestva zhizni naseleniya [Theoretical and Methodical Aspects of Investigating Social Standards of Living]. Irkutsk, Baikal State University of Economics and Law Publ., 2013. 180 p.

\section{Baikal Research Journal}




\section{Информация об авторах}

Седых Ольга Геннадьевна - кандидат экономических наук, доцент, кафедра социальной и экономической психологии, социологии и социальной работы, Байкальский государственный университет, 664003, г. Иркутск, ул. Ленина, 11, e-mail: sedyholga@yandex.ru.

Ильина Клавдия Далбаиновна - магистрант, кафедра социальной и экономической психологии, социологии и социальной работы, Байкальский государственный университет, 664003, г. Иркутск, ул. Ленина, 11, e-mail: ya.klava777@yandex.ru.

\section{Author}

Olga G. Sedykh - PhD in Economics, Associate Professor, Chair of Social and Economic Psychology, Sociology and Social Work, Baikal State University, 11 Lenin St., 664003, Irkutsk, Russian Federation; e-mail: sedyholga@yandex.ru.

Klavdiya D. Ilyina - Master Degree Student, Chair of Social and Economic Psychology, Sociology and Social Work, Baikal State University, 11 Lenin St., 664003, Irkutsk, Russian Federation; e-mail: ya.klava777@yandex.ru.

\section{Библиографическое описание статьи}

Седых О. Г. Социальная поддержка представителей коренных малочисленных народов в Иркутской области / О. Г. Седых, К. Д. Ильина // Baikal Research Journal. — 2017. T. 8, № 2. - DOI: 10.17150/2411-6262.2017.8(2).34.

\section{Reference to article}

Sedykh O. G., Ilyina K. D. Social support of representatives of indigenous low-numbered ethnic peoples in Irkutsk oblast. Baikal Research Journal, 2017, vol. 8, no. 2. DOI: 10.17150/2411-6262.2017.8(2).34. (In Russian).

\section{Baikal Research Journal}

